\title{
Alterations in fibrinolytic system proteins PAI-1, MMP-3, MMP-8, TIMP-1 and TIMP-2 in post-cholecystectomy bile duct injury
}

\author{
José Manuel Hermosillo-Sandoval ${ }^{1}$, Luis Miguel Román-Pintos ${ }^{2}$, Adolfo Daniel Rodríguez-Carrizález ${ }^{2}$, \\ Ernesto Germán Cardona-Muñoz ${ }^{2}$, Fermín Paul Pacheco-Moisés ${ }^{3}$, Genaro Gabriel Ortiz ${ }^{4}$, \\ Alejandra Guillermina Miranda-Díaz ${ }^{2 *}$ \\ ${ }^{1}$ Department of Surgery, Specialties Hospital of the National Occidental Medical Centre, Social Security Institute of Mexico \\ (Departamento de Cirugía, Hospital de Especialidades del Centro Médico Nacional de Occidente, Instituto Mexicano del Seguro \\ Social), Guadalajara, México \\ ${ }^{2}$ University Health Sciences Centre, University of Guadalajara (Centro Universitario de Ciencias de la Salud, Universidad de \\ Guadalajara), Guadalajara, México \\ ${ }^{3}$ University Centre for Exact and Engineering Sciences, University of Guadalajara (Centro Universitario de Ciencias Exactas e \\ Ingenierías, Universidad de Guadalajara), Guadalajara, México \\ ${ }^{4}$ Pathology and Oxidative Stress Laboratory, Division of Neurosciences, Occidental Biomedical Research Centre, Social Security \\ Institute of Mexico (Laboratorio de Estrés Oxidativo \& Patología, División de Neurociencias, Centro de Investigación Biomédica de \\ Occidente, Instituto Mexicano del Seguro Social), Guadalajara, México \\ Email: ${ }^{*}$ pachisquis@gmail.com
}

Received 13 June 2013; revised 15 July 2013; accepted 29 July 2013

Copyright (C) 2013 José Manuel Hermosillo-Sandoval et al. This is an open access article distributed under the Creative Commons Attribution License, which permits unrestricted use, distribution, and reproduction in any medium, provided the original work is properly cited.

\section{ABSTRACT}

Introduction: In bile duct injuries (BDI), cholestasis and cholangitis can alter the fibrinolytic system by promoting an increase of extracellular matrix depositions which favor an imbalance between metalloproteinases (MMPs) and their tissue inhibitors (TIMPs). Materials and Methods: Levels of PAI-1, MMP-3, MMP-8, TIMP-1 and TIMP-2 in 35 patients with post-cholecystectomy BDI by complete biliary obstruction were measured and compared to a healthy control group. Sirius red staining and immune staining for MMP-3 and MMP-8 were also undertaken in liver biopsies. Results: Levels of PAI-1, TIMP-1, TIMP-2 and MMP-8 were higher in BDI than healthy controls: $15 \pm 2 \mathrm{ng} / \mathrm{mL}$ vs $7.1 \pm 2 \mathrm{ng} / \mathrm{mL}(p<0.024)$; $539 \pm 64 \mathrm{ng} / \mathrm{mL}$ vs $256 \pm 13 \mathrm{ng} / \mathrm{mL}(p<0.003) ; 178.4 \pm$ $79.8 \mathrm{ng} / \mathrm{mL}$ vs $98.6 \pm 2 \mathrm{ng} / \mathrm{mL}$; and $90 \pm 10 \mathrm{ng} / \mathrm{mL}$ vs $6.8 \pm 2 \mathrm{ng} / \mathrm{mL}(p<0.002)$, respectively. However, serum levels of MMP-3 expression in BDI were decreased $9.0 \pm 1$ vs. healthy controls $20.3 \pm 6 \mathrm{ng} / \mathrm{mL}$ ( $p$ $<0.001)$. Morphometric analysis showed that Sirius red staining in BDI was increased 121548.6 \pm 20545.4 $\mu^{2}$ vs. $22865.7 \pm 3865{\mu m^{2}}^{2}$ in healthy controls $(p<$ 0.0001), MMP-8 deposition in liver was higher in BDI

${ }^{*}$ Corresponding author. compared to controls: $233015.2 \pm 32953.3{\mu m^{2}}^{2}$ vs. $30744.2 \pm 5810.2 \mathrm{\mu m}^{2}(p<0.0001)$. MMP-3 liver staining in BDI compared to healthy controls was not significant $130837.9 \pm 17,484{\mu m^{2}}^{2}$ vs. $116337.9 \pm$ $24803.3 \mu^{2}(p<0.55)$. These results suggest an imbalance between fibrogenic/fibrinolytic protein levels. Interestingly, expression of the fibrinolytic protein MMP-8 was increased in serum and liver biopsies in BDI. Conclusion: We found an imbalance of profibrogenic molecules which promote extracellular matrix deposition. The over-expression of fibrinolytic proteins such as MMP-8 could limit liver fibrosis, preventing hepatic dysfunction in post-cholecystectomy BDI.

Keywords: Cholecystectomy; Bile Duct Injury (BDI); Plasminogen Activator Inhibitor Type 1 (PAI-1); Tissue Inhibitors of Metalloproteinases (TIMP's);

Metalloproteinases (MMP's)

\section{INTRODUCTION}

In order to prevent excessive fibrin deposition during systemic and organ specific inflammatory processes, activation of the fibrinolytic system is essential. The fibrinolytic system is composed of activators and inhibit- 
tors that regulate the conversion of plasminogen to plasmin [1]. Plasminogen activator inhibitor type 1 (PAI-1) is a member of the super family of serine-protease inhibittors capable of activating plasminogen [2]. PAI-1 plays an important role in the regulation of fibrinolysis, it is synthesized by endothelial cells and hepatocytes, and is found in $90 \%$ of platelet granules and $10 \%$ of plasma where it circulates in its active form bound to the stabilizer protein vitronectin. At the endothelial level, PAI-1 synthesis is regulated by endotoxins, interleukin-1 beta (IL-1 $\beta$ ), tumor necrosis factor alpha (TNF- $\alpha$ ), thrombin, and diverse growth factors; while insulin is the primary regulator in hepatocytes [3]. PAI-1 can be found in latent form, active, or forming complexes with activators. Transforming growth factor-beta 1 (TGF- $\beta 1$ ) induces production of the PAI-1 through phosphorylation and nuclear translocation of the Smad proteins and promotes an increase of extracellular matrix (ECM) deposition.

ECM as an insoluble structure of proteins and carbohydrates produced by Kupffer and hepatic stellar cells (HSCs) serves as a support to the tissues. For satisfactory liver functions to occur, it is essential that ECM components have a constant and balanced dynamic between their synthesis and degradation. In this sense, Metalloproteinases (MMPs) are capable of degrading ECM components [4]. Clinical studies in animal models indicate that plasmin induces ECM degradation through activation of MMPs altering the fibrogenesis/fibrinolysis systems $[5,6]$. Since PAI-1 is produced directly by HSCs, these cells are responsible for the majority of ECM deposition during the fibrosis process in vitro and in vivo [7]. Furthermore, most MMPs are secreted as zymogen and are activated in the extracellular space through proteolysis. The propeptide of most MMPs can cleave through other MMPs or by plasmin [8].

MMP-3 (stromelysin-1) activates diverse precursor forms (pro-MMPs) and in this case, pro-MMP-1 activation is crucial for the generation of active MMP-1 [9]. TNF- $\alpha /$ IL- $1 \beta$ alone also induces the production of MMP-1, MMP-3 and MMP-9, which are released in latent form. Thrombin may induce the degradation of collagen as well by converting latent MMPs to active forms. Tissue inhibitors of metalloproteinases (TIMPs) are inhibited by the combination of thrombin and TNF- $\alpha /$ IL- $1 \beta[10]$.

TIMPs are natural inhibitors of the activity of MMPs [11]. TIMPs have an N-domain and C-terminal in amino acids 125 and 65, respectively, with three conserved disulfide bonds [12]. TIMP-1 inhibits activity of the majority of the MMPs, with the exception of MT1-MMP and MMP-2. It also unites with and inactivates MMP-1, MMP-2, MMP-3 and MMP-9. TIMP-2 is widely expressed and plays a dual role in the regulation of proMMP-2, and it also inhibits the activity of the majority of MMPs, except MMP-9 [13], since it has the capacity to form a complex with pro-MMP-9, blocking activation of the enzyme [14]. In addition, TIMP-1 and TIMP-2 can unite to the latent haemopexin domain of MMP-2 and MMP-9 [15].

While bile duct injuries (BDI) are complications of cholecystectomy, they are characterized by biliary obstructions of various magnitudes [16]. When biliary obstruction is complete, biliary cholestasis occurs with a grand capacity to cause cholangitis and activate hepatic and systemic inflammatory and fibrogenic processes [17]. Because there are no clinical reports that completely elucidate the mechanisms involved in the perpetuation of liver damage in post-cholecystectomy BDI, the purpose of our study was to find the potential alterations in systemic expression of fibrogenic/fibrinolytic proteins such as PAI-1, MMP-3, MMP-8, TIMP-1 and TIMP-2 in postcholecystectomy BDI and to determine in liver biopsies degree of fibrosis by morphometric analysis of collagen deposits with Sirius Red staining and liver expression of MMP-3 and MMP-8 with immunohistochemistry analysis.

\section{PATIENTS AND METHODS}

From 2005-2011, a prospective, transverse analytical study was performed and we included 35 patients suffering post-cholecystectomy BDI. They were characterized by complete biliary obstruction (those with partial obstruction or biliary leakage were excluded). Patients were classified by gender in 27 females and 8 males, with a ratio of 3.4:1. Average age was $44.5 \pm 3.2$ years. We also included healthy volunteers of similar ages and genders (27 female and 8 male) as a control group (for the blood test only), and 7 biopsies obtained from liver transplant donor patients for the normal morphometric analysis. Patients with BDI were sent to the Departamento de Cirugía General, Hospital de Especialidades, Centro Médico Nacional de Occidente, Instituto Mexicano del Seguro Social (IMSS), as the country's occidental tertiary care facility; to be subjected to the appropriate biliarydigestive reconstruction, according to the clinical characteristics of each patient.

\subsection{Clinical Manifestations}

BDI was present accidentally in 15 open and 20 laparoscopic cholecystectomies (routine, trans-operative cholangiography was not performed). The most common type of lesion was: Bismuth [18] III (15 patients), Bismuth II (13), Bismuth I (5), and Bismuth IV (2 patients). The injury was discovered during the cholecystectomy in 7 patients and was handled as follows: placement of the external biliary drainage and referral to the tertiary-care hospital. Biliary-digestive reconstruction was elective in every case at 6 weeks and the reconstruction included 25 Hepp-Couinaud procedures and $10 \mathrm{Y}$ de Roux. The av- 
erage surgical time was 6 hours.

This study was conducted in accordance with the Declaration of Helsinki (2000) and was approved by the IMSS Research Committee. Informed consent was obtained from all patients and healthy controls prior to study enrollment according to the ethical code of the institution. Identification numbers were assigned to assure patient confidentiality.

Pheripheral blood $(10 \mathrm{~mL})$ was withdrawn immediately prior to the onset of anaesthesia; blood samples were obtained by venipuncture and recollected in two vials $(5 \mathrm{~mL}$ each); one containing $0.1 \%$ of ethylenediamine-tetra-acetic acid (EDTA) for plasma and the other dry for serum. Plasma and serum were separated by centrifugation at $3000 \mathrm{rpm}$ for $10 \mathrm{~min}$ at room temperature and stored at $-80^{\circ} \mathrm{C}$ until use. The liver biopsy in the BDI group was performed as a routine clinical indication immediately prior to terminating the biliary-digestive deviation. Before surgical re-construction patients were subjected to external biliary drainage and their coagulation values were normalized to minimize risk of bleeding during surgery. In the operating room, whole blood, fresh frozen plasma and vitamin $\mathrm{K}$ were available.

\subsection{PAI-1, MMP-3, MMP-8, TIMP-1, and TIMP-2 ELISA}

Plasma levels of Human Serpin E1/PAI-1 quantikine (catalogue DSE100), serum levels of MMP-3 (catalogue DMP300), MMP-8 (catalogue DMP800), TIMP-1 (catalogue DTM100) and TIMP-2 (catalogue DTM200), were performed using ELISA kits (R\&D Systems ${ }^{\circledR}$ USA) following the manufacturer's protocols. All assays employed the quantitative sandwich enzyme immunoassay technique. A monoclonal antibody specific for Serpin E1, one polyclonal antibody specific for MMP-3 and one monoclonal antibody specific for MMP-8, one monoclonal antibody specific for TIMP-1, and a monoclonal antibody specific for TIMP-2 were pre-coated onto microplates. Standards and samples were pipetted into the wells and any Serpin E1, MMP-3, MMP-8, TIMP-1 and TIMP-2 present was bound by the immobilized antibody. After washing away any unbound substances an enzyme-linked polyclonal antibody specific for Serpin E1, MMP-3, MMP-8, TIMP-1 and TIMP-2 was added to the wells. Following the wash to remove any unbound antibody-enzyme reagent, the substrate solution was added to the wells and the color developed in proportion to the amount of Serpin E1, MMP-3, MMP-8, TIMP-1 and TIMP-2 bound in the initial step. Color development was stopped with sulfuric acid and the color intensity was measured at $450 \mathrm{~nm}$ of optical density.

\subsection{Evaluation of Liver Fibrosis}

Sirius red staining was used to quantify liver fibrosis.
The liver was diced into $5 \mathrm{~mm}$ sections, immersion fixed in PBS containing 4\% paraformaldehyde for 24 hours at $4^{\circ} \mathrm{C}$ and embedded in paraffin; and micrometer sections were mounted on glass slides. Sections were deparaffinized and the slides rehydrated with a wash for each 5-minute step: xylene (twice), 100\% ethyl alcohol (EtOH), 95\% EtOH, 70\% EtOH, 30\% EtOH, 1X PBS, and distilled water (twice). Sections were incubated for 2 hours at room temperature with an aqueous solution of saturated picric acid containing $0.1 \%$ fast green FCF and $0.1 \%$ direct red 80 . Tissue sections were covered with aluminum foil during the incubation. Stained slides were washed slowly under running distilled water for 6 minutes, dehydrated (3 minutes for each step) [19]. Sirius red staining was determined by morphometric analysis of liver biopsies in 10 random fields, using the image analysis software Axio-Vision 4.6.3 (Carl Zeiss) with 10X magnification, the results of which are expressed in $\mu \mathrm{m}^{2}$.

\subsection{Immunohistochemistry of Proteins MMP-3 and MMP-8}

Immunohistochemical reactions were performed by tissue incubations with their respective antibodies (MMP-3 y MMP-8). The secondary antibody used for the human MMP-3 and MMP-8 was an IgG polyclonal goat antibody. Each immunoglobulin was added according to the manufacturer's specifications (R\&D Systems ${ }^{\circledR}$ USA). Liver biopsies were fixed by immersion in a $4 \%$ paraformaldehyde solution with neutral $\mathrm{pH}$, and embedded in paraffin. $5 \mathrm{~mm}$ cuts were made and mounted on plates. Liver expression of MMP-3 and MMP-8 was determined through morphometric analysis with immunohistochemistry liver biopsies in 5 random fields, using the image analysis software Axio-Vision 4.6.3 (Carl Zeiss) with $10 \times$ magnification; the results are expressed in $\mu \mathrm{m}^{2}$.

\subsection{Statistical Analysis}

Statistical analysis was performed with SPSS. Quantitative variables were expressed as mean \pm SD and qualitative variables were expressed as frequencies and percentages. Data did not follow a normal distribution (Kolmogorov-Smirnov test); comparisons were analyzed using the Mann-Whitney $U$ test between groups for continuous variables. Pearson's correlation test was performed as well. A two tailed value of $p<0.05$ was considered significant, with a confidence interval of $95 \%$.

\section{RESULTS}

\subsection{Demographic Characteristics}

Table 1 demonstrates hepatic enzyme values on hospitalization admission and discharge. The length of in- 
Table 1. Liver enzimes at admission and hospital discharge. Hepatic enzymes. Adecrease in hepatic enzymes was observed between hospitalization admission and discharge after biliarydigestive reconstruction. The decrease of alkaline phosphatase on patients' hospital discharge was significant; however, in such a short period of time normalization of all enzyme levels was not achieved.

\begin{tabular}{|c|c|c|c|}
\hline & Normal value & BDI & $p$ \\
\hline AST & $\mathbf{U} / \mathbf{L}$ & \pm SD & \\
\hline Admission & $5-40$ & $163.41 \pm 141.95$ & \\
\hline Discharge & & $129.35 \pm 62.75$ & NS \\
\hline ALT & $\mathbf{U} / \mathbf{L}$ & \pm SD & \\
\hline Admission & $7-56$ & $140.47 \pm 87.53$ & \\
\hline Discharge & & $130.52 \pm 65.12$ & NS \\
\hline Total bilirubin & mg/dL & \pm SD & \\
\hline Admission & $0.3-1.9$ & $6.97 \pm 6.97$ & \\
\hline Discharge & & $4.39 \pm 4.39$ & NS \\
\hline Direct bilirubin & mg/dL & \pm SD & \\
\hline Admission & $0-0.3$ & $5.94 \pm 6.18$ & \\
\hline Discharge & & $3.37 \pm 4.48$ & NS \\
\hline ALP & IU/L & \pm SD & \\
\hline Admission & $20-140$ & $596 \pm 101$ & \\
\hline Discharge & & $280 \pm 47$ & 0.0060 \\
\hline Prothrombin time & Seconds & \pm SD & \\
\hline Admission & $10-14$ & $15.85 \pm 2.90$ & \\
\hline Discharge & & $14.11 \pm 2.40$ & NS \\
\hline Albumin & g/dL & \pm SD & \\
\hline Admission & $3.5 \%-5.4 \%$ & $3 \pm 1$ & \\
\hline Discharge & & $4 \pm 1$ & NS \\
\hline
\end{tabular}

Aspartate-amino-transferase (AST), Alanine-amino-transferase (ALT), Alkaline phosphatase (ALP), \pm Standard deviation (SD).

hospital stay was short (average 9 days), during which time the tendency for the enzymes to normalize was observed. There was a significant decrease in the alkaline phosphatase on discharge $(p<0.006)$, although the abnormally increased rates persisted. Neither patient had a history of drug or excessive alcohol use, nor were there reports of known hepatic illness before the cholecystectomy. We emphasize that despite the external biliary drainage prior to biliary-digestive reconstruction, BDI patients intermittently presented cholangitis with symptoms characterized by fever, jaundice, weight loss, nausea and vomiting. Histopathology reports of liver biopsies obtained during surgical reconstruction included: cholestasis, reactive hepatitis, steatohepatitis, and peri- portal fibrosis. We also report that we had no fatalities within our study group.

\subsection{Fibrinolytic System Proteins}

Human Serpin E1/PAI-1 plasma levels in the control group were significantly lower than in $\mathrm{BDI} ; 7.1 \pm 2.2$ $\mathrm{ng} / \mathrm{mL}$ vs. $15.7 \pm 2.2 \mathrm{ng} / \mathrm{mL}$, respectively $(p<0.024)$. This suggests the existence of an active, persistent inflammatory state capable of producing an imbalance in ECM depositions. Since PAI-1 actively participates in the regulation of fibrinolysis, it induces inhibition of proteases that depend on the fibrinolytic activity, and promotes accumulation of ECM, favoring hepatic fibrosis in BDI (Graph 1(a)). Because PAI-1 is considered an acute phase protein that can be induced during the inflammatory state, this finding of elevated PAI-1 plasma levels could possibly produces hepatic fibrosis.

Serum levels of MMP-3 were higher in the control group than the BDI group; with $20.3 \pm 6.4 \mathrm{ng} / \mathrm{mL}$ vs. 9.6 $\pm 1.1 \mathrm{ng} / \mathrm{mL}$, respectively. ( $p<0.001$ ) (Graph 1(b)). MMP-3 is an important member of the family of MMPs which is primarily produced by HSCs, fibroblasts, smooth muscle cells and macrophages. Since the expression of MMP-3 is transitory and occurs primarily within the first hours after a lesion, it could be considered that diminished serum levels in BDI could be due to its saturation in hepatic tissue, or that it was inactivated by the over expression of plasma PAI-1 or TIMPs; which in turn, could also contribute to the progression of ECM deposition, causing dysfunction and fostering liver rigidity.

It has been reported that MMP-8 is a collagenase secreted by neutrophils whose primary role is to degrade collagen type 1 in ECM, and when neutrophils are decreased, or at normal levels, the expression of MMP-8 can also be diminished. In the present study, the level of expression of MMP-8 is demonstrated in Graph 1(d), where serum levels in BDI were significantly higher compared to the control group; $90.4 \pm 10.7 \mathrm{ng} / \mathrm{mL}$ vs. 6.8 $\pm 2.2 \mathrm{ng} / \mathrm{mL}(p<0.002)$. This could be attributed to episodes of cholangitis present in patients, with an increase of circulating polymorphonuclears capable of perpetuating the phase of inflammation present in the liver gland in BDI. The over expression of MMP-8 could also participate in BDI by trying to compensate or limit the excessive deposition of some ECM pro-fibrogenic molecules.

Serum levels of TIMP-1 in the control group were lower than the BDI group; $256.2 \pm 14 \mathrm{ng} / \mathrm{mL}$ vs. $539.8 \pm$ $64.1 \mathrm{ng} / \mathrm{mL}$, respectively $(p<0.003)$ (Graph 1(c)). TIMP-1 is capable of inhibiting MMP-3 by regulating the repair of hepatic tissue. The significant increase of TIMP-1 could translate as the imbalance in favor of the production of pro-fibrogenic molecules (PAI-1, TGF- $\beta$ ) 


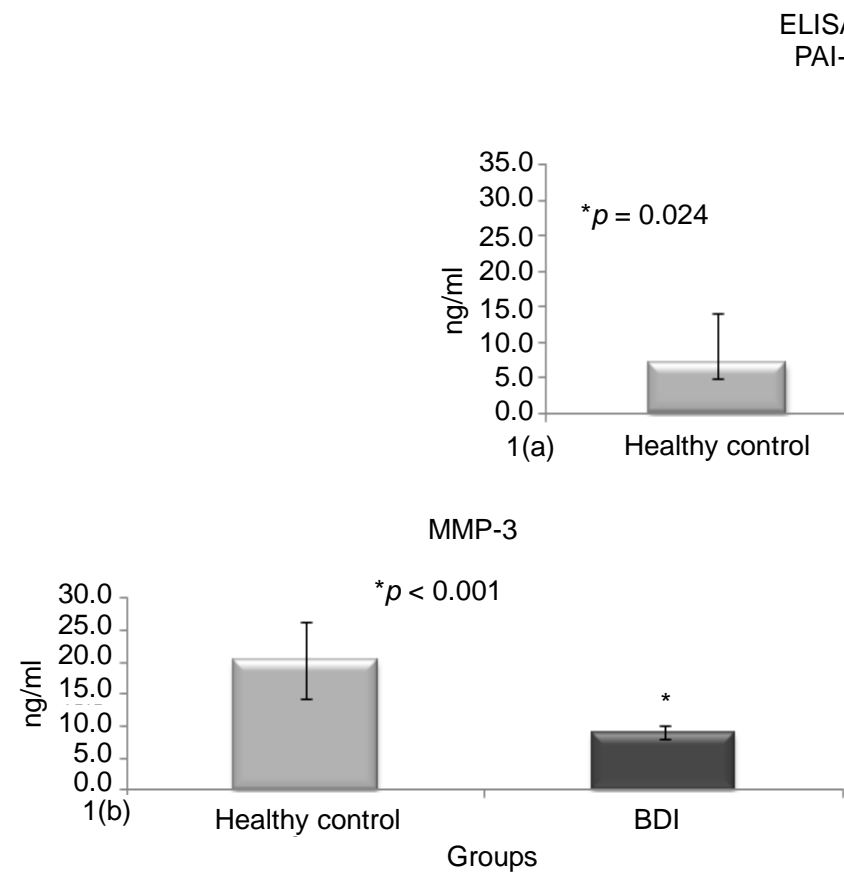

ELISAS
PAI-1

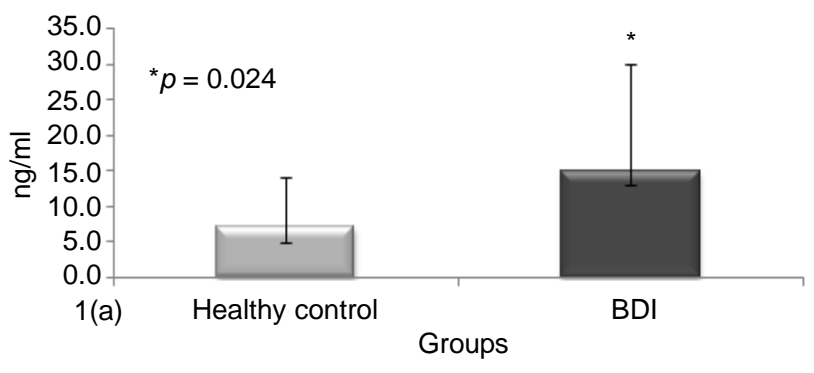

MMP-3

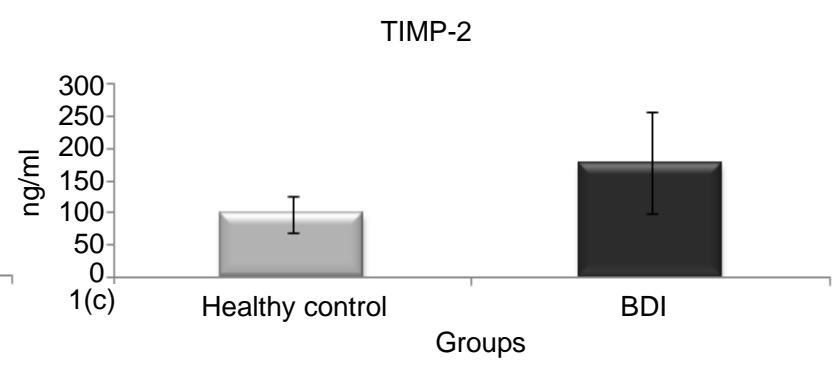

MMP-8

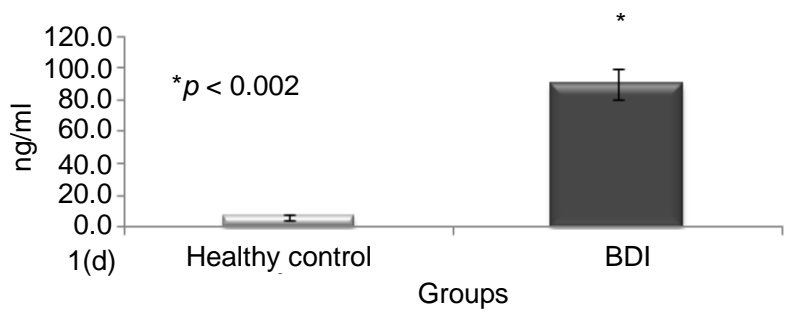

TIMP-1

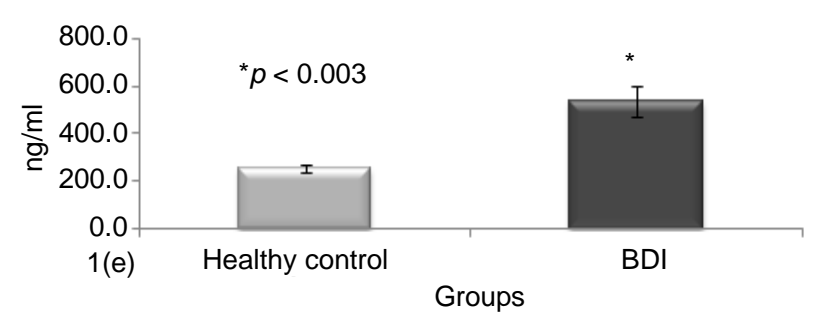

Graph 1. LEVELS OF PAI-1, MMP-3, MMP-8, TIMP-1 Y TIMP-2. (1(a)) Over expression of plasma PAI-1 was obtained in BDI vs. healthy controls. In contrast, no significant serum expression of MMP-3 was presented in BDI (1(b)). Serum levels of TIMP-2 and TIMP-1 were increased in BDI, although TIMP-1 was significantly over expressed vs. healthy controls $(p<0.003)$; confirming the imbalance present in BDI between the pro-fibrogenic molecules PAI-1, TIMP-1 and TIMP-2 vs. the fibrinolytic ones, were there was a clear inhibition of MMP-3. Interestingly, serum over expression of MMP-8 in BDI was observed; which, could translate as an intention to limit the depositing of pro-fibrotic molecules in the liver as a compensatory effect of MMP-8.

vs. the fibrinolytic molecules (MMPs). Serum levels of TIMP-2 were also higher in BDI vs. controls; $178.4 \pm$ $79.8 \mathrm{ng} / \mathrm{mL}$ vs. $98.6 \pm 2 \mathrm{ng} / \mathrm{mL}$, thus this difference was not significant (Graph 1(e)). The increase in TIMP-2 contributes to the disequilibrium between the inflammatory/pro-fibrogenic molecules present in BDI.

\subsection{Hepatic Collagen Deposition}

Sirius red stains in red the deposited liver collagens and the rest of the tissue green. In BDI liver biopsies, a significant increase in collagen deposits was found; $121548.6 \pm 20545.5 \mu \mathrm{m}^{2}$ vs. healthy controls $22865.8 \pm$ $3865 \mu \mathrm{m}^{2}(p<0.0001)$; this is possibly due to the over expression of PAI-1 and the deregulation found between the MMPs and TIMPs (Graphs 2(a)-2(c)).

\subsection{Immunohistochemistry of MMP-3 and MMP-8 Proteins}

In the morphometric analysis of healthy liver samples, MMP-3 was slightly lower in the control group than the BDI group; with $116337.9 \pm 24803.3 \mu^{2}$ vs. $130837.9 \pm$ $17,484 \mu \mathrm{m}^{2}$, respectively $(p<0.55)$ (Graphs 3(a)-3(c)). We point out that slight increase in the expression of MMP-3 in liver tissue was insufficient in order to combat the excessive collagen deposition aided by the over expression of molecules such as PAI-1 and the TIMPs in liver biopsies of patients with BDI. In relation to the MMP-8 secreted by neutrophils, the significant increase of MMP-8 expression in BDI liver tissues is noteworthy: BDI $233015.2 \pm 32953.3 \mu \mathrm{m}^{2}$ vs. healthy controls $30744.1 \pm 5810.1 \mu \mathrm{m}^{2}(p<0.0001)$ (Graphs 3(d)-3(f)). 

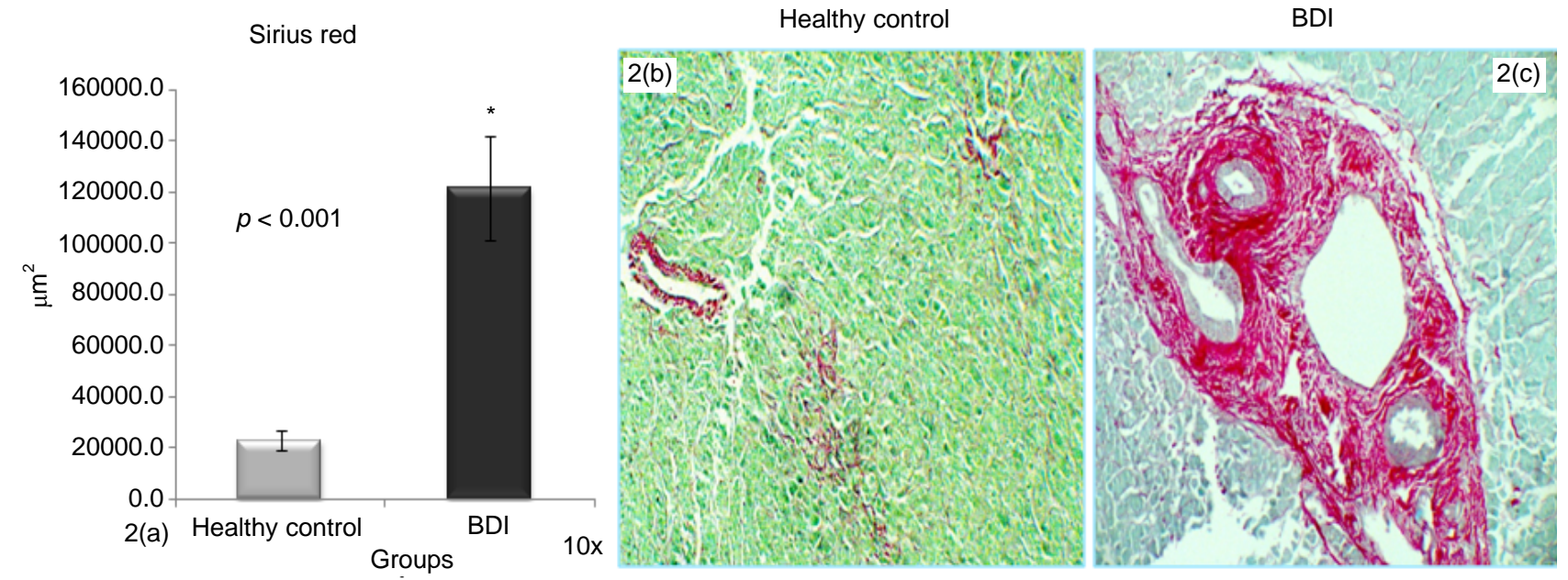

Graph 2. Morphometric analysis of sirius red in liver biopsies. (2(a)-2(c)) Sirius red deposits were greater in BDI group vs. control group.

Sirius red

Ab anti MMP-3

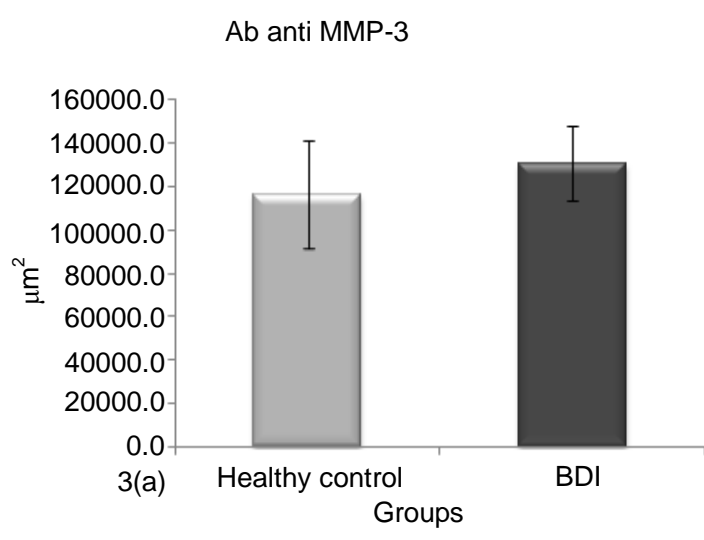

Ab anti MMP-8

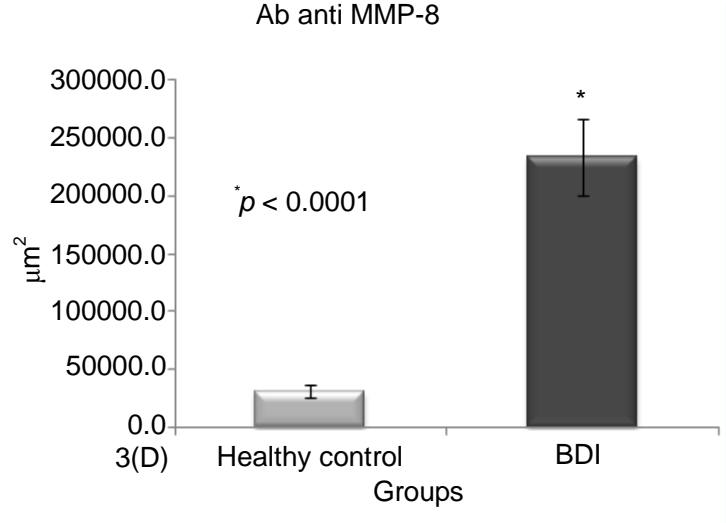

Healthy control
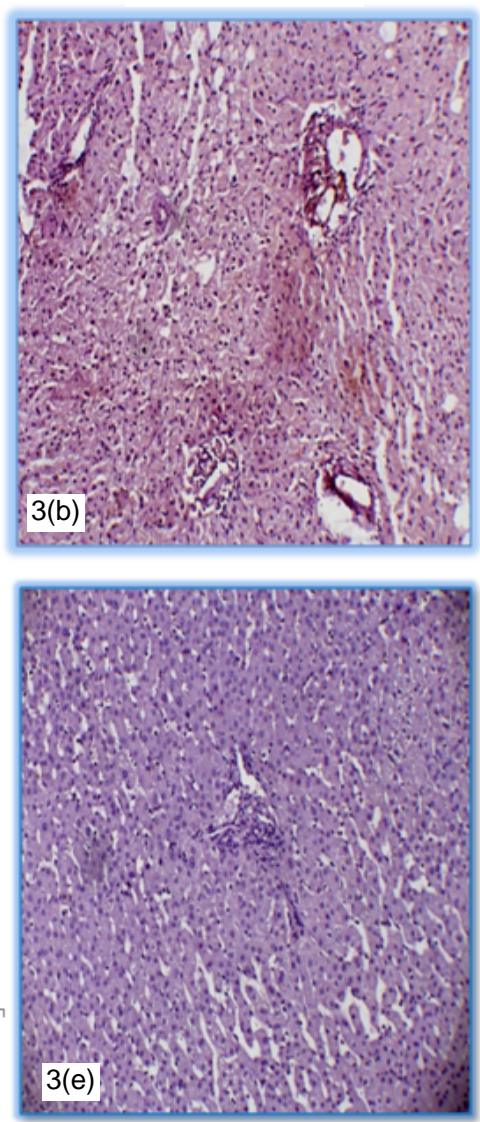

$10 \mathrm{x}$
BDI
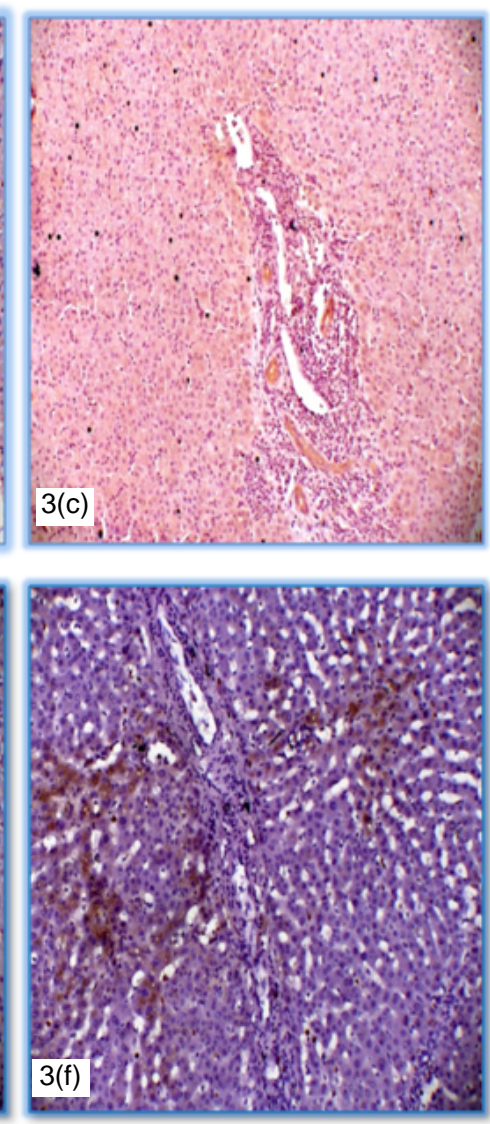

Graph 3. Morphometric analysis of MMP-3 and MMP-8 in liver biopsies. MMP-3 (3(a)) in biopsies of donated liver was not significantly different vs. BDI, as shown in images (3(b) and 3(c)). The significant over expression of MMP-8 in BDI liver tissue vs. the biopsies of healthy liver is noteworthy. The over expression of MMP-8 could play an important compensatory role in trying to limit the deposition of pro-fibrogenic macromolecules (3(d)-3(f)). 
The over expression of MMP- 8 could be explained by the neutrophils' attempt to control and limit the excessive ECM deposition brought about by cholestasis and cholangitis as well as by the over expression of PAI- 1 in BDI. We found a positive Pearson's correlation test between serum levels of TIMP-2 and the increase of hepatic MMP-8 depositions $\left(\mathrm{R}^{2}=0.3, p<0.04\right)$ in BDI.

\section{DISCUSSION}

BDI represents one of the most complex and serious surgical complications that increases risk of death in patients [20]. The prevalence of BDI during open cholecystectomy is estimated at $0.1 \%-0.2 \%$ [21]. BDI is characterized by chronic inflammation and obliteration of the intra and extra-hepatic bile ducts. In the present study, BDI predominated in young women, with a female to male ratio of 3.4:1 and a high risk of premature death. In this respect, the most important risk factors reported for gallstones are: age, female gender, pregnancy and obesity [22]. However, BDI in males is high (8) and being male is considered an independent risk factor for suffering BDI [23].

The fibrinolytic system is controlled by PAI- 1 which is produced by platelets, endothelial cells and HSCs and under normal conditions PAI-1 is usually found in low concentrations [24]. PAI-1 is also a major regulator; it blocks the conversion of plasminogen to plasmin by preventing the activation of MMPs. During the hepatic fibrosis process, PAI-1 is over expressed due to the activation of pro-inflammatory cytokines and pro-fibrogenic TGF- $\beta$, among others. Inhibition of MMPs is also carried out by tissue inhibitors of MMPs by inhibiting the proteolytic activity of plasmin-activated MMPs. Over-expression of these inhibitors is directed by TGF- $\beta$ to promote fibrosis deposition [24]. TGF- $\beta$ is a multifunctional cytokine involved in regulation, differentiation, and proliferation of ECM. TGB- $\beta$ also has an important role in hepatic fibrogenesis since it activates the over expression of ECM deposits through molecules like PAI-1, TIMPs, collagens, tenascin, fibronectin, and Smad7, as previously reported by our group [25]. In the present study, plasma levels of PAI-1 were higher in BDI compared to healthy controls, which could explain the activation and facilitation of the fibrous tissue deposition in the liver with BDI as well as the very important role PAI- 1 has in inhibiting the activation of MMP-3 upon favouring activation of TIMPs [26]. In this sense, the balance between PAI-1, MMPs and TIMPs is lost and the progression of hepatic fibrosis is encouraged.

Lately, the measurement of fibrosis has acquired importance in clinical trials. Data regarding comparative advantages of measurement methods for fibrosis are limited; however, morphometric analysis of collagen depos- its using Sirius red staining proves to be useful and reliable [27], and is appropriate for visualization of collagen fibers and staging of hepatic fibrosis [28]. In our study, there was a significant increase in BDI collagen deposits, demonstrating the deregulation between the fibrogenic/ fibrinolytic proteins in the short period of time between the appearance of the biliary lesion and the biliary-digestive repair (6 weeks), which emphasizes the speed and severity of the functional alterations that are produced in the liver.

The MMP family is involved in the degradation of ECM in normal physiological processes such as embryonic development, reproduction, and tissue remodeling, as well as disease processes such as cancer. Degradation of ECM in the liver is carried out primarily by action of four enzymes MMP-1, MMP-2, MMP-3 and MMP-9. MMPs can be activated by action of urokinase plasminogen activator and by the same MMPs [29]. Interestingly, in this study serum levels and hepatic expression of MMP-3 were not significant in BDI, in contrast to the increased plasma PAI-1 and serum TIMP-1 and MMP-8, which emphasize the imbalance between the pro-fibrogenic/fibrinolytic systems. The morphometric analysis of MMP-3 in liver biopsies did not indicate significant expression of MMP-3 in BDI patients vs. healthy liver tissue; differing from one recent study performed in children with biliary atresia and jaundice (neonatal liver pathology with repercussions similar to BDI in adults) that reported increased serum levels of MMP-3 [30]. It is important to mention that MMP-3 is not specific towards one substrate alone since it relies on an ample margin of degradation proteins such as laminin, fibronectin, proteoglycans, and to a lesser degree some types of MMPs, collagen and gels that were not quantified in this study [12]. Furthermore, MMP-3 has the ability to activate MMP-1 and MMP-9 and is essential for protein degradation of ECM during the fibrosis process [31]. It is synthesized as a latent active proenzyme, with a molecular weight of $57 \mathrm{kDa}$ and $45 \mathrm{kDa}$ [32]. The locus is located at the $11 \mathrm{q} 22.2$ gene and MMP-3 belongs to the stromelysins family [33]. The hemopexin-type region is responsible for regulating its substrate binding and TIMPs. The amino and carboxyl terminal also interacts in the binding to TIMPs [34]. MMP-3 can be inhibited by the over expression of PAI-1 and TIMPs by forming a 1:1 stoichiometric complex in the catalytic domain of the MMPs and thus blocking MMPs; even when they were previously activated, as it could occur in BDI [35]. On the other hand, MMP-3 inhibition is associated with hepatic dysfunction and liver stiffness and could play a role in the pathophysiology of hepatic fibrosis in postcholecystectomy BDI as it has been reported in chronic viral liver disease, especially in cirrhosis [36].

The importance of TIMPs when inhibiting ECM deg- 
radation has been demonstrated in cell cultures by separating TIMPs from MMPs in animal models and clinical studies of hepatic fibrosis. This has been reported specifically in liver transplantation where a significant increase in the expression of TIMP-1 and TIMP-2 has been found. In addition, changes in TIMP-1 mRNA for patients with sclerosing cholangitis, biliary atresia, primary biliary cirrhosis and autoimmune chronic active hepatitis have been reported [37]. In our study, levels of TIMP-1 and TIMP-2 were elevated in BDI, although only TIMP-1 was statistically significant, it has the ability to inhibit MMP-3. Previously, the rapid and significant over expression of TIMP-1 in the chronic phase has been reported in experimental studies of animals subjected to bile duct ligation [38]. The role of TIMP-1 in inhibiting matrix degradation has been shown through apoptosis regulation of some cell types.

Triple helical molecules are relatively resistant to protease activity but are cleaved at a specific Gly-Ile/Leu site in their $\alpha$-chain by interstitial neutrophil collagenase (MMP-8). MMP-8 is essential for the activity and reabsorption of collagen deposits during the successful repair of hepatic fibrosis [39]. In addition, it has been demonstrated that the depletion of Kupffer cells diminishes the quantity of neutrophils and consequently MMP8 expression. The obstruction of the intra and extra-hepatic biliary ducts (cholestasis) caused by BDI induces a pattern of hepatic damage consisting in hyperplasia of the epithelial duct, infiltration of inflammatory cells (monocytes and neutrophils) [40], and the production of periportal fibrosis $[41,42]$. Interestingly, serum and hepatic expression of MMP-8 in postcholecystectomy BDI was significantly increased, possibly in an attempt to control or limit the excessive deposition of fibrous tissue in the liver through persistent activation of HSCs trying to balance pro-fibrogenic/fibrinolytic activity. The fibrinolytic effect of MMP-8 in degradation of collagen type 1 , including diminishing the expression of TGF- $\beta$, the activation of MMPs and the regenerative state of the liver in animal models, has already been pondered [43].

The criteria and management options in BDI are limited and possibly inadequate; for this reason the aim of this study was to comprehend the pathophysiological mechanisms that lead to hepatic and systemic lesion in postcholecystectomy BDI, and in accordance with other studies, it could be useful for the development of new therapeutic strategies. We conclude that in BDI, an imbalance is present between the expression of pro-fibrogenic (PAI-1, TIMP-1 and TIMP-2) vs. fibrinolytic molecules, as shown by serum and hepatic decrease of MMP3. Serum and hepatic over expression of MMP-8 is noteworthy as it may contribute to the fibrinolysis equilibrium by limiting liver fibrosis and rigidity and preventing early liver dysfunction in post-cholecystectomy
BDI.

Limitations in the present study include its transversal design and regarding patient care, it lacks long term follow-up consultations as patients are returned to their respective primary medical care units three months after the biliary-digestive deviation (if they do not present any early complications). According to the results reported here, patients should return for follow-up every six months to five years, or beforehand if complications were to occur.

\section{ACKNOWLEDGEMENTS}

The authors thank Rogelio Troyo Sanromán M in Sc, for his untiring help and valuable assistance in the statistical analysis of the data and Michele Brennan, $\mathrm{M}$ in Sc, Clinical Chemistry, for the review of the English language editing.

\section{REFERENCES}

[1] Quax, P.H., van den Hoogen, C.M., Verheijen, J.H., Padro, T., Zeheb, R., Gelehrter, T.D., van Berkel, T.J., et al. (1990) Endotoxin induction of plasminogen activator and plasminogen activator inhibitor type $1 \mathrm{mRNA}$ in rat tissues in vivo. The Journal of Biological Chemistry, 265, 15560-15563.

[2] Kruithof, E.K. (1988) Plasminogen activator inhibitors: A review. Enzyme, 40, 113-121.

[3] Bergheim, I., Guo, L., Davis, M.A., Duveau, I. and Arteel, G.E. (2006) Critical role of plasminogen activator inhibitor-1 in cholestatic liver injury and fibrosis. Journal of Pharmacology and Experimental Therapeutics, 316, 592600. doi:10.1124/jpet.105.095042

[4] Bataller, R. and Brenner, D.A. (2005) Liver fibrosis. Journal of Clinical Investigation, 115, 209-218.

[5] Ramos-DeSimone, N., Hahn-Dantona, E., Sipley, J., Nagase, H., French, D.L. and Quigley, J.P. (1999) Activation of matrix metalloproteinase-9 (MMP-9) via a converging plasmin/stromelysin-1 cascade enhances tumor cell invasion. The Journal of Biological Chemistry, 274, 1306613076. doi:10.1074/jbc.274.19.13066

[6] Huang, Y., Haraguchi, M., Lawrence, D.A., Border, W.A., Yu, L. and Noble, N.A. (2003) A mutant, noninhibitory plasminogen activator inhibitor type 1 decreases matrix accumulation in experimental glomerulonephritis. Journal of Clinical Investigation, 112, 379-388.

[7] Leyland, H., Gentry, J., Arthur, M.J. and Benyon, R.C. (1996) The plasminogen-activating system in hepatic stellate cells. Hepatology, 24, 1172-1178 doi:10.1002/hep.510240532

[8] Amălinei, C., Căruntu, I.D. and Bălan, R.A. (2007) Biology of metalloproteinases. Romanian Journal of Morphology and Embryology, 48, 323-334.

[9] Visse, R. and Nagase, H. (2003) Matrix metalloproteinases and tissue inhibitors of metalloproteinases: Structure, function, and biochemistry. Circulation Research, 92, 827-839. doi:10.1161/01.RES.0000070112.80711.3D 
[10] Fang, Q., Liu, X., Al-Mugotir, M., Kobayashi, T., Abe, S., Kohyama, T., et al. (2006) Thrombin and TNF-alpha/ IL-1beta synergistically induce fibroblast-mediated collagen gel degradation. American Journal of Respiratory Cell and Molecular Biology, 35, 714-721. doi:10.1165/rcmb.2005-0026OC

[11] English, J.L., Kassiri, Z., Koskivirta, I., Atkinson, S.J., Di Grappa, M., Soloway, P.D., Nagase, H., et al. (2006) Individual Timp deficiencies differentially impact proMMP-2 activation. The Journal of Biological Chemistry, 281, 10337-10346. doi:10.1074/jbc.M512009200

[12] Lee, M.H. and Murphy, G. (2004) Matrix metalloproteinases at a glance. Journal of Cell Science, 117, 40154016. doi: $10.1242 /$ jes. 01223

[13] Folgueras, A.R., Pendás, A.M., Sánchez, L.M. and López-Otín, C. (2004) Matrix metalloproteinases in cancer: From new functions to improved inhibition strategies. The International Journal of Developmental Biology, 48, 411-424. doi:10.1387/ijdb.041811af

[14] Collette, T., Bellehumeur, C., Kats, R., Maheux, R., Mailloux, J., Villeneuve, M. and Akoum, A. (2004) Evidence for an increased release of proteolytic activity by the eutopic endometrial tissue in women with endometriosis and for involvement of matrix metalloproteinase-9. Human Reproduction, 19, 1257-1264. doi:10.1093/humrep/deh290

[15] Seo, D.W., Li, H., Guedez, L., Wingfield, P.T., Diaz, T., Salloum, R., Wei, B.Y. and Stetler-Stevenson, W.G. (2003) TIMP-2 mediated inhibition of angiogenesis: An MMP-independent mechanism. Cell, 114, 171-180. doi:10.1016/S0092-8674(03)00551-8

[16] Nuzzo, G., Giuliante, F., Giovannini, I., Ardito, F., D’Acapito, F., Vellone, M., Murazio, M., et al. (2005) Bile duct injury during laparoscopic cholecystectomy: Results of an Italian national survey on 56,591 cholecystectomies. Archives of Surgery, 140, 986-992. doi:10.1001/archsurg.140.10.986

[17] Miranda-Díaz, A.G., Hermosillo-Sandoval, J.M., HuertaRosas, G., López-Guillén, G.G., Cardona-Muñoz, E.G., García-Iglesias, T., Pacheco-Moisés, F., et al. (2010) Tumor necrosis factor-alpha and interleukin-6 levels among patients suffering a bile duct injury during cholecystectomy. Revista Medica de Chile, 138, 1259-1263.

[18] Tocchi, A., Costa, G., Lepre, L., Liotta, G., Mazzoni, G. and Sita, A. (1996) The long-term outcome of hepaticojejunostomy in the treatment of benign bile duct strictures. Annals of Surgery, 224, 162-167. doi:10.1097/00000658-199608000-00008

[19] Canbay, A., Guicciardi, M.E., Higuchi, H., Feldstein, A., Bronk, S.F., Rydzewski, R., Taniai, M., et al. (2003) Cathepsin B inactivation attenuates hepatic injury and fibrosis during cholestasis. Journal of Clinical Investigation, 112, 152-159.

[20] Takeda, K., Kojima, Y., Ikejima, K., Harada, K., Yamashina, S., Okumura, K., Aoyama, T., et al. (2008) Death receptor 5 mediated-apoptosis contributes to cholestatic liver disease. Proceedings of the National Academy of Sciences of USA, 105, 10895-10900. doi: $10.1073 /$ pnas.0802702105
[21] Parmeggiani, D., Cimmino, G., Cerbone, D., Avenia, N., Ruggero, R., Gubitosi, A., Docimo, G., et al. (2010) Biliary tract injuries during laparoscopic cholecystectomy: Three case reports and literature review. Giornale $d i$ Chirurgia, 3, 16-19.

[22] Constantinescu, T., Huwood, A., Jabouri, A.K., Brãtucu, E., Olteanu, C., Toma, M. and Stoiculescu, A. (2012) Gallstone disease in young population: Incidence, complications, therapeutic approach. Chirurgia, 107, 579582.

[23] Nieuwenhuijs, V.B. (2011) Bile duct injury and use of cholangiography during laparoscopic cholecystectomy. British Journal of Surgery, 98, 391-396. doi:10.1002/bjs.7335

[24] Sentíes-Gómez, M.D., Gálvez-Gastélum, F.J., MezaGarcía, E. And Armendáriz-Borunda, J. (2005) Hepatic fibrosis: Role of matrix metalloproteases and TGFbeta. Gaceta Médica de México, 141, 315-322.

[25] del-Pilar-Alatorre-Carranza, M., Miranda-Díaz, A., YañezSánchez, I., Pizano-Martínez, O., Hermosillo-Sandoval, J.M., Vázquez-Del Mercado, M., Hernández-Hoyos, S., et al. (2009) Liver fibrosis secondary to bile duct injury: Correlation of Smad7 with TGF-beta and extracellular matrix proteins. BMC Gastroenterology, 9, 81 . doi:10.1186/1471-230X-9-81

[26] Arthur, M.J. (2000) Fibrogenesis II. Metalloproteinases and their inhibitors in liver fibrosis. American Journal of Physiology Gastrointestinal and Liver Physiology, 279, G245-G249.

[27] Farris, A.B., Adams, C.D., Brousaides, N., Della Pelle, P.A., Collins, A.B., Moradi, E., Smith, R.N., Grimm, P.C. and Colvin, R.B. (2011) Morphometric and visual evaluation of fibrosis in renal biopsies. Journal of the American Society of Nephrology, 22, 176-186. doi:10.1681/ASN.2009091005

[28] Lopez-De Leon, A. and Rojkind, M. (1985) A simple micromethod for collagen and total protein determination in formalin-fixed paraffin-embedded sections. Journal of Histochemistry \& Cytochemistry, 33, 737-743. doi: $10.1177 / 33.8 .2410480$

[29] Friedman, S. (2003) Liver fibrosis-from bench to beside. Journal of Hepatology, 38, s38-s53. doi:10.1016/S0168-8278(02)00429-4

[30] Honsawek, S, Praianantathavorn, K., Chongsrisawat, V., Vejchapipat, P., Theamboonlers, A. and Poovorawan, Y. (2011) High serum matrix metalloproteinase-3 and liver stiffness in postoperative biliary atresia. Pediatric Surgery International, 27, 681-687. doi:10.1007/s00383-010-2816-x

[31] Murphy, G., Stanton, H., Cowell, S., Butler, G., Knäuper, V., Atkinson, S., et al. (1999) Mechanism for pro-matrix metalloprotease activation. APMIS, 107, 38-44. doi:10.1111/j.1699-0463.1999.tb01524.x

[32] Westermark, J. and Kähäri, V.M. (1999) Regulation of matrix metalloproteases expression tumor invasión. FASEB Journal, 13, 781-792.

[33] Egebled, M. and Zena, W. (2002) New functions of the maatrix metalloproteases in cáncer progression. Nature Reviews Cancer, 2, 161-174. doi:10.1038/nrc745 
[34] Wallon, M. and Christopher, M.O. (1997) The hemopexin like domain (C domain) of human gelatinase A (matrix metalloprotease -2 ) requires $\mathrm{Ca} 2+$ for fibronectin and heparin binding. $J B C, \mathbf{2 7 2 , 7 4 7 3 - 7 4 8 1 .}$ doi:10.1074/jbc.272.11.7473

[35] Egeblad, M. and Werb, Z. (2002) New functions for the matrix metalloproteinases in cancer progression. Nature Reviews Cancer, 2, 161-174. doi:10.1038/nrc745

[36] Watanabe, N., Nishizaki, Y., Kojima, S., Takashimizu, S., Nagata, N., Kagawa, T., et al. (2006) Clinical significance of sesrum matrix metalloproteinases and tisue inhibitors of metalloproteinasses in chronic liver disease. The Tokai Journal of Experimental and Clinical Medicine, 31, 86-91.

[37] Arthur, M.J.P. (2002) Fibrogenesis II. Metalloproteinases and their inhibitors in liver fibrosis. American Journal of Physiology Gastrointestinal and Liver Physiology, 279, G245-G249.

[38] Nie, Q.H., Duan, G.R., Luo, X.D., Xie, Y.M., Luo, H., Zhou, Y.X. and Pan, B.R. (2004) Expression of TIMP-1 and TIMP-2 in rats with hepatic fibrosis. World Journal of Gastroenterology, 10, 86-90.

[39] Harty, M.W., Muratore, C.S., Papa, E.F., Gart, M.S.,
Ramm, G.A., Gregory, S.H. and Tracy Jr., T.F. (2010) Neutrophil depletion blocks early collagen degradation in repairing cholestatic rat livers. American Journal of $\mathrm{Pa}$ thology, 176, 1271-1281. doi:10.2353/ajpath.2010.090527

[40] Roggin, K.K., Kim, J.C., Kurkchubasche, A.G., Papa, E.F., Vezeridis, A.M. and Tracy, T.F. (2001) Macrophage phenotype during cholestatic injury and repair: The persistent inflammatory response. Journal of Pediatric Surgery, 36, 220-228. doi:10.1053/jpsu.2001.20059

[41] Tracy, T.F., Goerke, M.E., Bailey, P.V., Sotelo-Avila, C. and Weber, T.R. (1993) Growth-related gene expression in early cholestatic liver injury. Surgery, 114, 532-537.

[42] Saito, J.M. and Maher, J.J. (2000) Bile duct ligation in rats induces biliary expression of cytokine-induced neutrophil chemoattractant. Gastroenterology, 118, $1157-$ 1168. doi:10.1016/S0016-5085(00)70369-6

[43] Siller-López, F., Sandoval, A., Salgado, S., Salazar, A. Bueno, M., Garcia, J., Vera, J., et al. (2004) Treatment with human metalloproteinase- 8 gene delivery ameliorates experimental rat liver cirrhosis. Gastroenterology, 126, 1122-1133. doi:10.1053/j.gastro.2003.12.045 